\title{
Cipango
}

Cipango Cahiers d'études japonaises

$20 \mid 2013$

Nouveaux regards sur les arts de la scène japonais I

\section{Départ pour la pérégrination vers l'Ouest (1971)}

\section{Yutaka Higashi}

Traducteur : Toshio Takemoto

\section{(2) OpenEdition}

\section{Journals}

Édition électronique

URL : https://journals.openedition.org/cipango/1983

DOI : 10.4000/cipango.1983

ISSN : 2260-7706

Éditeur

INALCO

Édition imprimée

Date de publication : 30 octobre 2013

ISSN : 1164-5857

\section{Référence électronique}

Yutaka Higashi, «Départ pour la pérégrination vers I'Ouest (1971)», Cipango [En ligne], 20 | 2013, mis en ligne le 17 avril 2015, consulté le 30 juin 2021. URL : http://journals.openedition.org/cipango/1983 ; DOI : https://doi.org/10.4000/cipango.1983

Ce document a été généré automatiquement le 30 juin 2021.

\section{(c) (7) (8)}

Cipango est mis à disposition selon les termes de la Licence Creative Commons Attribution - Pas d'Utilisation Commerciale 4.0 International. 


\title{
Départ pour la pérégrination vers l'Ouest (1971)
}

\author{
Yutaka Higashi \\ Traduction : Toshio Takemoto
}

\section{NOTE DE L'AUTEUR}

HIGASHI Yutaka 東由多加, «Saiyūki e no shuppatsu 西遊記への出発 » in Higashi Yutaka ga nokoshita kotoba 東由多加が遺した言葉 Mots laissés par Higashi Yutaka), Tōkyō, Jiritsu shobō 而立書房, 2002, p. 23-26. Dans le roman chinois la Pérégrination vers l'ouest, un moine bouddhiste accompagné d'étranges novices - dont le plus connu est le Roi des singes - effectue un voyage de quatorze années vers une utopie. Il serait tentant d'effectuer un parallèle entre les aventures de cette troupe et la tournée des Tōkyō Kid Brothers en Europe, où Higashi est appelé pour mettre en scène The Story of Eight Dogs (voir plus bas, n. 5) au Teatro de Arte à Rome, en 1971.

1 Il s'est écoulé bien longtemps depuis que, après un appel courageux à passer de la scène à la rue, de l'illusion à la réalité, les hommes de théâtre, ayant perdu la force de s'envoler vers le monde de la fiction, s'appliquent illusoirement à voler de leurs propres ailes ou à marcher sur la corde raide, en un équilibre délicat entre scène et réalité. J'en étais moi aussi venu à tenir le violent dispositif de la réalité pour unique arrière-plan au théâtre. Un détournement d'avion! Si j'avais pu battre des ailes au point de décoller de cette réalité, j'aurais pu m'envoler vers la Corée du Nord ou vers Cuba. Jadis, je passais mon temps en solitaire, dans les ténèbres de la réalité.

2 Mais cette réalité me fait bâiller à m'en décrocher la mâchoire à présent. Elle n'offre aucun intérêt, elle me stimule à peine, cette réalité-là. Elle n'engendre qu'une autre réalité. La mort d'un politique étonne les lecteurs des journaux ? Elle finira ensevelie au cimetière qui porte le nom de vie quotidienne. Les membres des Beatles se séparent? On n'entendra même plus "Yesterday " sur les chaines stéréo. Je n'ai désormais besoin ni d'argent ni de femme. Je n'achète ni hebdomadaire ni mensuel. Il me suffit de vivre 
aussi résolument que Robinson Crusoé. À Tōkyō, dans un studio de télévision, dans le métro ou au café, dans un article de journal et dans un disque, j'imagine "une île déserte ", et je me contente de vivre les heurs et malheurs de Robinson Crusoé. Après quoi, je marche en direction de cette «île déserte» et j'appareille vers mon paradis, que j'appelle « l'utopie du cerisier ».

Découvrir une infinité de Robinson Crusoé contemporains, c'est ça, pour moi, le "théâtre ». "Tōkyō Kid Brothers » et "Voyageurs Kid » sont des terres à la dérive pour cette infinité de Robinson Crusoé, des arches errant sur la «mer » des illusions.

En pleine nuit, j'imagine une étoile filante invisible, et je tente de partir pour la "Pérégrination vers l'Ouest ", à la recherche du Tripitaka ${ }^{2}$ : la discipline monastique, les paroles de Bouddha, ses enseignements... Pas question de partir aux États-Unis ou en Europe. Peu importe si ce n'est pas la Route de la Soie! Peu importe si nous prenons Aéroflot via l'Union soviétique. N'est-ce pas? Nous essayons de ne pas tenir compte de la réalité, nous, les Tōkyō Kid Brothers, car en réalité nous ne pouvons aller en Chine. L'« utopie du cerisier » est donc un habit fait pour moi. Sans aller jusqu'à la " passion de l'antiquité » de Schliemann, je m'en vais découvrir à tout prix un endroit meilleur que la réalité, au Japon ou en Europe. Ce voyage, ce sera mon «journal de la dérive du cerisier ".

$5 \mathrm{Vu}$ le discours que je tiens, on raille le « gentil Japonais » que je suis, mais je m'en fiche. Je suis un escroc qui ose adresser des mots doux à une réalité qui n'est pas douce, j'habite complètement dans un monde de fiction et de fantaisie. J'en suis réduit à ne croire qu'au théâtre. Bref, je ne crois qu'en cette «fête ». Je vous le dis tout net : je suis un fêtard, moi ! Holà ! Si les feux d'artifice de notre fête s'éteignent, je disparais avec eux. Si je pouvais juste une fois faire la fête de l'utopie du cerisier, je deviendrais paysan, sérieux, pas de problème! Comme je crois en la "fête », en " nous ", en « tout un chacun", je suis d'un optimisme inné, tel ce gars qui cherche comme un fou le trésor du Capitaine Kidd. Cet étrange voyage en mer n'est que le tribord de mon théâtre, ma vie, ma pensée. Démuni de sagesse, je ne saurais vivre sans illusions, je vis dans ma honte et je dis : «barre à tribord, toute!»

Chanson « Discours sur le bonheur»

Résous l'énigme de Maeterlinck

Achète la carte de l'île au trésor

Poursuis le paon rouge ${ }^{3}$.

Pour être heureux

Tu n'as qu'à emprunter la route des rêves du soir au matin

Jusqu'où va le train de nuit de la Voie lactée?

Endosse la chemise de Sinbad le marin

Sois capitaine de l'Hispaniola

Danse avec le vent, disparu comme par enchantement

Pour être heureux

Tu n'as qu'à emprunter la route de la soie d'ici jusque là-bas.

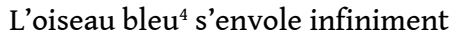

Ma Légende des huit chiens, c'est un récit qui court jusqu'à l'obtention du passeport pour aller du village de Nansō Satomi ${ }^{5}$ à l'utopie du cerisier. Le récit de la dérive sur la route de la soie, du visage isolé dans la foule jusqu'au " corps communautaire ». C'est la fête d'amour des rêveurs qui rêvent, la comédie musicale de cette utopie. L'ambition de faire revivre ce drame de la rencontre, dite "Légende des huit chiens », en " légende » 
actuelle n'avait nulle importance à mes yeux. Je voulais juste, dans ma dérive avec les "Voyageurs Kid», fuir la réalité du dépit humain. C'est ce que j'ai écrit dans le prospectus de notre spectacle « La légende des huit chiens » à Tōkyō.

7 J'aime verser des larmes, je suis un homme qui vit dans un mélodrame qui déborde de sentimentalisme. Il se peut que je me mette à marcher, désormais, non seulement loin de la réalité, mais aussi du «théâtre ». Je veux juste rêver. Même si le départ pour « La pérégrination vers l'ouest » implique une navigation plus longue que celle du «Voyage en Europe en cent vingt jours $»^{6}$, je ne m'éveillerai pas de ce rêve, pas question! Je râle, mais pourquoi ne pas partir ensemble? La vérité, c'est que je me sens seul, et que je ne fais que pleurer dans les ténèbres de l'illusion de l'utopie. Comme dans un mélodrame, je vous le dis, non seulement pour moi, mais à vous tous aussi : notre pensée, notre " isme ", notre vie, notre amour, nos larmes, notre théâtre, notre arme, notre mère, notre mode de vie, notre avenir, notre pays, notre horizon, c'est et ce n'est que "l'utopie du cerisier», et cela seul suffit. Je dis adieu au reste. L'expérience de la séparation, j'ai connu ça, je suis un adulte. Ainsi, je suis aussi résolu que Robinson Crusoé. Notre "Légende des huit chiens » déborde de la tragédie d'un homme qui n’a jamais fait que rêver, à tel point que c'en est pitoyable. C'est bien pour ça qu'elle vaut le coup d'œil : pleurez, je vous prie!

Cette nuit, coup de téléphone d'un garçon de dix-huit ans : «Je téléphone partout dans le monde ». Quoi ? Je téléphone au rêve ? Qu'il y vienne, le voleur de téléphone! Lui, c'est le bonze Xuanzang ${ }^{7}$, et moi, l'arrière-petit-fils de Sun Wukong ${ }^{8}$. Bon, partons en voyage en utopie, et vers l'Ouest, je suis le singe dans la paume du bouddha ${ }^{9}$. Écoutezmoi bien, vous autres qui fuyez le rêve aux aurores! Vous ne pouvez lui échapper, quand bien même vous seriez coureur de fond solitaire.

\section{NOTES}

1. Les Voyageurs Kid sont des personnes - environ quatre-vingts - qui ont rejoint les Tōkyō Kid Brothers pour voyager avec eux en Europe.

2. «Trois corbeilles » : titre honorifique pour les moines ayant la maîtrise de l'ensemble du canon bouddhiste (les « trois corbeilles » justement).

3. S'agit-il d'un clin d'œil à Miyazawa Kenji 宮沢賢治 (1896-1933) qui évoque périodiquement le paon dans ses contes? La référence à Miyazawa et à son célèbre Train de nuit dans la voie lactée (Ginga tetsudō no yoru 銀河鉄道の夜) est beaucoup plus claire au $6^{\mathrm{e}}$ vers.

4. Higashi revient à Maeterlinck, qu'il cite au premier vers : l'auteur belge a écrit l'Oiseau bleu en 1908.

5. Situé dans l'actuel département de Chiba, ce village est l'un des cadres spatiaux du Nansō Satomi Hakkenden 南総里見八犬层 (1814-1842), roman épique de Kyokutei Bakin 曲亭馬琴 dont Higashi a repris en partie le titre pour la pièce des Tōkyō Kid Brothers The Story of Eight Dogs (Hakkenden八犬层) ; Sur le roman de Bakin voir l'article de Fanny BERTU, http://cipango.revues.org/ 391.

6. Référence inconnue. Entre 1969 et 1973, le nombre de Japonais effectuant un voyage à l'étranger passe de 50000 à 230000 , soit une augmentation annuelle de plus de $50 \%$. Le récit de 
voyage d'Oda Makoto 小田実 Nandemo miteyarō 何でも見てやろう (Tout voir ! ; 1961) devient «la Bible » des jeunes voyageurs nippons.

7. Le moine bouddhiste du Saiyūki.

8. Le héros dudit roman.

9. Ce héros est un singe qui se croit grand voyageur. En fait, il n'a fait que danser dans la paume du bouddha. 